\title{
Clinical utility of circulating tumor cell measurement in the diagnosis of indeterminate lesions of the pancreas
}

\author{
Satvinder Mudan $\dagger$, Alexandros Giakoustidis, Andrew V Thillainayagam, \\ Jimmy Jacob \& Justin Stebbing* \\ ${ }^{\dagger}$ Author for correspondence: Department of Surgery, Royal Marsden Hospital, Fulham Road, London. \\ SW3 6JJ, UK - Tel.: +44 2078178015 - Fax: +44 2078082805 - satvinder.mudan@rmh.nhs.uk \\ 'All authors were involved in study concept and design; acquisition of data; analysis and interpretation of \\ data; drafting of the manuscript; critical revision of the manuscript and approval of the final version.
}

The quantification of circulating tumor cells has been historically problematic due to the different methods applied to their measurement. Following the development of standardized technology, they are now becoming well-established prognostic and predictive markers in patients with breast, colon and prostate cancer. While they represent a real-time noninvasive test, their use in diagnostics has seldom been reported. We report their use to help diagnose an indeterminate pancreatic mass. The use of an automated circulating tumor cell platform as described is likely to have utility as an aid to differential diagnosis, although larger studies will be required to ascertain its positive or negative predictive value.

The prognostic role of circulating tumor cells (CTCs) is now established $[1,2]$, and there are data supporting their role as more reproducible indications of disease status than current imaging methods, raising the possibility that changes in CTCs could be used to predict clinical benefit [3]

The ability to isolate, quantify and molecularly categorize CTCs is a tremendous challenge [4]. A number of methodologies have been proposed for their measurement, including quantitative real-time PCR-based assays [5-7], immunomagnetic separation and laser scanning cytometry [8-11]. Following these data, the US FDA has now approved the routine use of the bead-based fluorescence CellSearch ${ }^{\circledR}$ system (Veridex, NJ, USA) in a number of clinical settings, including breast and prostate cancer - diseases that are considered incurable when metastatic - in order to determine prognosis. Their role in prediction has become established following the discovery that therapies that decrease their number are associated with improved outcomes [4,12-14].

The use of CTCs measured by this system in patients with pancreatic cancer has seldom been reported [15]. As pancreatic lesions are often difficult to biopsy, we report on the use of CTCs in an individual with a pancreatic mass to facilitate diagnosis.

\section{Patient \& methods}

A 72-year-old man with an unremarkable past medical history, apart from chronic alcohol use, presented with intermittent abdominal pain for several months, leading to an unrevealing gastroscopy, colonoscopy and abdominal ultrasound. He had few systemic symptoms and routine laboratory tests gave no further information. The pain then radiated to his back, and computed tomography revealed a $7 \times 8 \times 5 \mathrm{~cm}$ mass at the tail of his pancreas with features compatible with either a large cyst, similar to those often seen in alcoholic pancreatitis, or a carcinoma (Figure 1). At that time, his carcinoembryonic antigen (CEA) was $27.2 \mathrm{ng} / \mathrm{ml}$ and his carbohydrate antigen (CA)19-9 measured $1413 \mathrm{IU} / \mathrm{ml}$.

The CellSearch system was then used to enrich and enumerate his CTCs, as we have described previously [16]. A $7.5 \mathrm{ml}$ peripheral blood sample was taken in a CellSave ${ }^{\circledR}$ (Veridex LLC, NJ, USA) preservative tube, kept at room temperature and processed within $72 \mathrm{~h}$. The system enriched for epithelial cell adhesion molecule (EpCAM)-positive epithelial cells by incubating the sample with ferrofluid conjugated to anti-EpCAM antibodies. Cells were stained with the following fluorescent-labeled monoclonal proprietary antibodies: CD45APC, to distinguish the CTCs from leukocytes, and pan-cytokeratin 8, 18 and 19 (CK-PE), to stain epithelial cells. Nucleic acids were stained using 4,6-diamidino-2-phenylindole (to exclude red blood cells). The sample was then scanned on the CellTracks analyzer $\mathrm{II}^{\circledR}$ (Veridex) fluorescent microscope for analysis, as described previously [14,17].

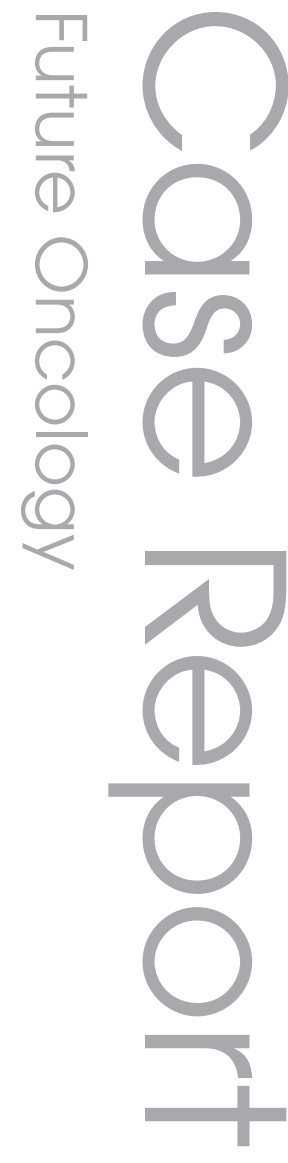

\section{Keywords}

- circulating tumor cells - diagnosis $=$ pancreatic cancer

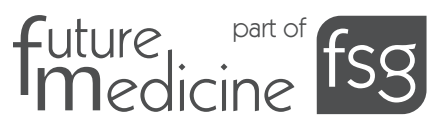




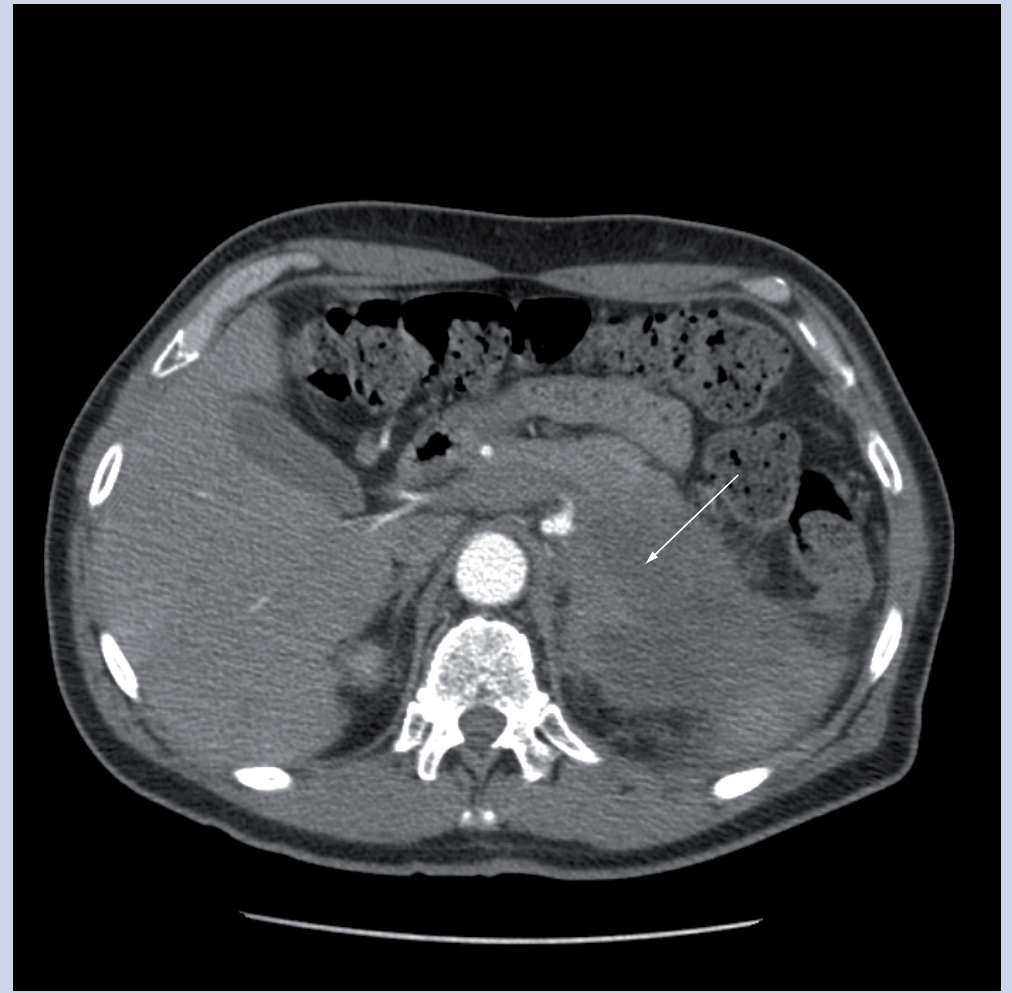

Figure 1. A computed tomography image of the indeterminate mass arising from the tail of the pancreas (arrow).
Pancreatic lesions are well known for their lack of accessibility, and often the diagnosis of carcinoma is only made following surgical resection. Fine-needle aspirates are often inconclusive, and radiologic appearances of benign and metastatic lesions are often similar. Major surgical procedures with associated morbidity, such as pylorus-preserving pancreaticoduodenectomies or Whipple's procedures, have been performed for benign but suspicious-appearing lesions. However, technologies such as this are limited by false-positives and -negatives, and the possibility that nonepithelial malignant cancers, such as neuroendocrine tumors, may arise from the pancreas. In addition, the CellSearch system would not distinguish primary and metastatic lesions, and does not allow light microscopy of the cells detected. While a cut-off of five CTCs is typically used for both prognostic and predictive purposes in breast cancer $[1,2]$, such delineation requires further study in this setting.

Allard et al. described the existence of CTCs in the peripheral blood of all patients with major carcinomas, but not in healthy subjects with nonmalignant diseases [17]; CTCs, as assessed by the CellSearch System, are not found in nonmalignant pancreatic diseases, such as chronic pancreatitis [15].

Despite years of research and hundreds of reports on tumor markers in oncology, the number of biomarkers that have emerged as clinically useful is very small, with initial promise replaced by inconsistent data $[18,19]$. While the use of CTCs as a prognostic and predictive marker is now accepted, we report here its use in defining the likely underlying pathology of an indeterminate abdominal lesion. The use of a standardized and automated CTC platform as described is likely to have utility in facilitating diagnosis, although prospective studies will be required to ascertain its positive or negative predictive value and determine the true clinical benefit of CTC measurement.

While it is difficult to draw conclusions from cohort studies, if CTC assays could lead to the earlier diagnosis of pancreatic cancer, this would be a remarkable accomplishment. The presence of CTCs is unlikely to be a false-positive and, as such, larger studies will be required to determine their predictive value.

\footnotetext{
Acknowledgements

The authors wish to thank Dr Maurice Slevin for his help with this case.
} 


\section{Financial \& competing interests \\ disclosure}

The authors have no relevant affiliations or financial involvement with any organization or entity with a financial interest in or financial conflict with the subject matter or materials discussed in the manuscript. This includes employment, consultancies, honoraria, stock ownership or options, expert testimony, grants or patents received or pending, or royalties.

No writing assistance was utilized in the production of this manuscript.

\section{Bibliography}

1. Cristofanilli M, Budd GT, Ellis MJ et al.: Circulating tumor cells, disease progression, and survival in metastatic breast cancer. N. Engl. J. Med. 351(8), 781-791 (2004).

2. Cristofanilli M, Hayes DF, Budd GT et al.: Circulating tumor cells: a novel prognostic factor for newly diagnosed metastatic breast cancer. J. Clin. Oncol. 23(7), 1420-1430 (2005).

3. Budd GT, Cristofanilli M, Ellis MJ et al.: Circulating tumor cells versus imaging predicting overall survival in metastatic breast cancer. Clin. Cancer Res. 12(21), 6403-6409 (2006).

4. Stebbing J, Jiao LR: Circulating tumor cells as more than prognostic markers. Lancet Oncol. 10(12), 1138-1139 (2009).

5. Stathopoulou A, Vlachonikolis I, Mavroudis D et al: : Molecular detection of cytokeratin-19-positive cells in the peripheral blood of patients with operable breast cancer: evaluation of their prognostic significance. J. Clin. Oncol. 20(16), 3404-3412 (2002).

6. Benoy IH, Elst H, Philips M et al.: Real-time RT-PCR detection of disseminated tumor cells in bone marrow has superior prognostic significance in comparison with circulating tumor cells in patients with breast cancer. Br. J. Cancer 94(5), 672-680 (2006).

7. Gervasoni A, Monasterio Munoz RM, Wengler GS, Rizzi A, Zaniboni A, Parolini O: Molecular signature detection of circulating tumor cells using a panel of selected genes. Cancer Lett. 263(2), 267-279 (2008).
8. Smith BM, Slade MJ, English J et al.: Response of circulating tumor cells to systemic therapy in patients with metastatic breast cancer: comparison of quantitative polymerase chain reaction and immunocytochemical techniques. J. Clin. Oncol. 18(7), 1432-1439 (2000).

9. Ring AE, Zabaglo L, Ormerod MG, Smith IE, Dowsett M: Detection of circulating epithelial cells in the blood of patients with breast cancer: comparison of three techniques. Br. J. Cancer 92(5), 906-912 (2005).

10. Pachmann K, Clement JH, Schneider CP et al.: Standardized quantification of circulating peripheral tumor cells from lung and breast cancer. Clin. Chem. Lab. Med. 43(6), 617-627 (2005).

11. Pachmann K, Camara O, Kavallaris A et al.: Monitoring the response of circulating epithelial tumor cells to adjuvant chemotherapy in breast cancer allows detection of patients at risk of early relapse. J. Clin. Oncol. 26(8), 1208-1215 (2008).

12. Apostopolous C, Giamas G, Stebbing J: Clinical significance of circulating tumor cells. Biomarkers 1, 9-11 (2007).

13. Rack BK, Schindlbeck A, Schneeweiss J et al.: Prognostic relevance of circulating tumor cells (CTCs) in peripheral blood of breast cancer patients before and after adjuvant chemotherapy: the German SUCCESS-Trial. J. Clin. Oncol. 26(Suppl.) (2008) (Abstract 503).

14. Payne RE, Yague E, Slade MJ et al.: Measurements of EGFR expression on circulating tumor cells are reproducible over time in metastatic breast cancer patients. Pharmacogenomics 10(1), 51-57 (2009).

15. Kurihara T, Itoi T, Sofuni A et al:: Detection of circulating tumor cells in patients with pancreatic cancer: a preliminary result. J. Hepatobiliary Pancreat. Surg. 15(2), 189-195 (2008).

16. Slade MJ, Payne R, Riethdorf S et al.: Comparison of bone marrow, disseminated tumor cells and blood-circulating tumor cells in breast cancer patients after primary treatment. Br. J. Cancer 100(1), 160-166 (2009).
17. Allard WJ, Matera J, Miller MC et al.: Tumor cells circulate in the peripheral blood of all major carcinomas but not in healthy subjects or patients with nonmalignant diseases. Clin. Cancer Res. 10(20), 6897-6904 (2004).

18. McShane LM, Altman DG, Sauerbrei W, Taube SE, Gion M, Clark GM: REporting recommendations for tumor MARKer prognostic studies (REMARK). Nat. Clin. Pract. Urol. 2(8), 416-422 (2005).

19. McShane LM, Altman DG, Sauerbrei W, Taube SE, Gion M, Clark GM: REporting recommendations for tumor MARKer prognostic studies (REMARK). Breast Cancer Res. Treat. 100(2), 229-235 (2006).

\section{Affiliations}

- Satvinder Mudan

Department of Surgery, Royal Marsden Hospital, Fulham Road, London,

SW3 6JJ, UK

Tel.: +44 2078118015

Fax: +442078082805

satvinder.mudan@rmh.nhs.uk

- Alexandros Giakoustidis The London Clinic, London, UK

- Andrew V Thillainayagam Gastroenterology and Hepatology Unit, Hammersmith Hospital, Imperial College Healthcare Trust, London, UK

- Jimmy Jacob Department of Oncology, Hammersmith Hospital, Imperial College Healthcare Trust, London, UK

- Justin Stebbing, MA MRCP FRCPath PhD Imperial College Healthcare NHS Trust, Charing Cross Hospital, 1st Floor, E Wing, Fulham Palace Road, London, W6 8RF UK Tel.: +442087468295 Fax: +442088461433 j.stebbing@imperial.ac.uk 